\title{
A EMENDA CONSTITUCIONAL № 6 DE 1995 E O PROCESSO DE DESNACIONALIZAÇÃO DOS RECURSOS MINERAIS NO BRASIL
}

http://dx.doi.org/10.21527/2176-6622.2020.53.196-205

Recebido em: 30/10/2019

Aceito em: 20/1/2020

Matheus Amorim de Oliveira Andrade

Graduação em Direito pela Universidade Presbiteriana Mackenzie (2018). Mestrando em Direito Político e Econômico na Universidade Presbiteriana Mackenzie. http://lattes.cnpq.br/3401858025626011. https:// orcid.org/0000-0002-1431-4313. mathrod2010@hotmail.com

\section{Daniel Francisco Nagao Menezes}

Graduação em Direito (PUC-Campinas). Especializações em Direito Constitucional e Direito Processual Civil (PUC-Campinas) e em Didática e Prática Pedagógica no Ensino Superior (Centro Universitário Padre Anchieta). Mestrado e Doutorado em Direito Político e Econômico (Universidade Presbiteriana Mackenzie-SP). Pós-Doutorado em Direito (Fadusp). Professor do Programa de Pós-Graduação em Direito Político e Econômico da Faculdade de Direito da Universidade Presbiteriana Mackenzie. Membro do Ciriec-Brasil. http:// lattes.cnpq.br/4101655062938301. https://orcid.org/0000-0001-9151-5699. nagao.menezes@gmail.com

\section{RESUMO}

O Brasil é um país rico em recursos minerais. Tais recursos já pertenceram desde a coroa aos donos do território onde se encontravam as minas. Com a Revolução de 1930 e o Nacional Desenvolvimentismo de Getúlio Vargas, o Estado brasileiro adotou uma postura nacionalizante dos recursos minerais, buscando industrializar o país e obter independência financeira. Embora o período do regime militar tenha tentado flexibilizar tal postura, permitindo o investimento estrangeiro na mineração, a Constituição de 1988 trouxe de volta o enfoque nacionalista aos recursos minerais, buscando favorecer a empresa de capital nacional na exploração destes bens, entrementes as propostas neoliberais da década de 90, o leilão da Vale do Rio Doce e a aprovação da Emenda Constitucional no 6 de 1995, que retirou a distinção entre empresa brasileira de capital nacional e empresa brasileira de capital estrangeiro, provocaram a chamada "desnacionalização do recursos minerais" no Brasil. Buscando demonstrar como a aprovação da EC no 6/95 tem impactado negativamente no desenvolvimento econômico e tecnológico da indústria por meio de uma revisão bibliográfica e análise documental, conclui-se que, com a permissão da entrada massiva de capital estrangeiro neste mercado e atuação de multinacionais, que não possuem a intenção de desenvolver a indústria nacional, mas somente exportar commodities, faz-se necessário uma política que privilegie a empresa de capital nacional, por intermédio da edição de leis ordinárias para tal, e que busque promover o desenvolvimento econômico e tecnológico retomando o crescimento da indústria nacional, tratando os recursos minerais como bens estratégicos.

Palavras-chave: Política dos recursos minerais. Emenda constitucional no 06/1995. Desenvolvimento econômico e industrial.

\section{CONSTITUTIONAL AMENDMENT NO. 6 OF 1995 AND THE DENATIONALIZATION PROCESS OF MINERAL RESOURCES IN BRAZIL}

\section{ABSTRACT}

Brazil is a country rich in mineral resources. These resources already belonged from the crown to the owners of the territory where the mines were located. With the 1930 Revolution and Getúlio Vargas National Developmentalism, the Brazilian State adopted a nationalizing attitude of mineral resources, seeking to industrialize the country and achieve financial independence. Although the period of the military regime attempted to relax such a stance by allowing foreign investment in mining, the 1988 Constitution brought back the nationalist approach to mineral resources seeking to favor the national capital enterprise in exploiting these goods, meanwhile, the neoliberal proposals of the 90 s, the auction of Vale do Rio Doce and the approval of the Constitutional Amendment no 6 of 1995, which removed the distinction between a Brazilian company with a national capital and a Brazilian company with a foreign capital, caused the so-called "denationalization of mineral resources" in Brazil. Seeking to demonstrate how the approval of the Constitutional Amendment $n=06 / 95$ has negatively impacted the economic and technological development of the industry through a literature review and document analysis, it is concluded that, with the permission of the massive entry of foreign capital in this market and multinational performance, which do not intend to develop the national industry, but only export commodities, it is necessary a policy that favors the national capital company, through ordinary laws, and that seeks to promote economic and technological development by resuming the growth of national industry, treating mineral resources as strategic assets.

Keywords: Mineral resources policy. Constitutional amendment no 06/1995. Economic and industrial development.

\section{SUMÁRIO}

1 Introdução. 2 Histórico do direito minerário até a revolução de 1930. 3 A nacionalização dos recursos minerais e o início da atuação de empresas estrangeiras no ramo da mineração no Brasil. 4 A abordagem nacionalista da Constituição Federal de 1988. 5 A emenda constitucional no 6 de 1995 e a privatização da Companhia Vale do Rio Doce. 6 O contexto atual da emenda constitucional no 6 de 1995. 7 Conclusão. 8 Referências. 


\section{INTRODUÇÃO}

Conforme ocorreu a Revolução Industrial no século 19 e o desenvolvimento das Indústrias nos países pioneiros, a demanda para suprir o estilo de vida capitalista da nova sociedade de consumo em massa fez surgir a necessidade de obter suprimentos advindos, em grande parte, dos recursos minerais (CAVALCANTI, 2003). A principal política dos países de centro, como denomina Celso Furtado, é de adquirir o abastecimento seguro destes recursos a preços baixos (BERCOVICI, 2011a), a fim de perpetuar suas formas de vida.

O Brasil, um país de dimensões continentais, possui muitas riquezas minerais. Tais riquezas já pertenceram desde a Coroa Portuguesa até os proprietários do terreno onde se encontravam minérios em seu subsolo. A Constituição de 1988, por outro lado, abraçou um viés nacionalista do Direito Minerário, que já maturava na nossa legislação desde a Carta Magna de 1934, em favor de uma política econômica de proteção e incentivo da criação de uma indústria nacional, com o objetivo de converter a exploração do meio ambiente em desenvolvimento tecnológico e econômico para o país.

Com o advento da Emenda Constitucional no 6 de 1995 e com a privatização da Companhia Vale do Rio Doce, entretanto, há uma mudança neste ideário, com a permissão da entrada massiva e majoritária de capital estrangeiro nas empresas mineradoras, provocando o que foi chamado, por Gilberto Bercovici (2011a), de "desnacionalização dos recursos minerais".

Este artigo busca demonstrar, por meio de uma revisão bibliográfica e análise documental, como esse fenômeno de desnacionalização dos recursos minerais foi prejudicial ao desenvolvimento econômico e tecnológico do nosso país, analisando a forma como os recursos minerais eram tratados pela legislação até a revolução de 1930, as mudanças que este período, marcado pelo Nacional Desenvolvimentismo de Getúlio Vargas, trouxe com a adoção de um viés nacionalista na exploração dos recursos minerais e sua posterior flexibilização no regime militar, em prol da entrada de capital estrangeiro no setor minerário, a reafirmação do enfoque nacionalista pela Constituição Federal de 1988, a aprovação da Emenda Constitucional no 6/95 e a mudança da posição ideológica do constituinte, e, por fim, o contexto atual da emenda, suas consequências e como tal panorama pode ser revertido.

\section{HISTÓRICO DO DIREITO MINERÁRIO ATÉ A REVOLUÇÃO DE 1930}

A história do Direito Minerário brasileiro está intimamente ligada à evolução científica que o acompanhou. Nesse sentido, desde o Brasil Colônia, onde adotava-se a teoria do Metalismo, que quantificava a riqueza pela quantidade de metais preciosos possuídos, até a atualidade, muitas mudanças legislativas ocorreram.

Durante todo o período do Brasil Colonial, quando as capitanias hereditárias fixavam políticas que convinham à realeza, todos os minérios pertenciam à Coroa. Sua exploração dependia da autorização do monarca (sistema Regaliano), que recebia o pagamento do quinto (20\%) do metal extraído, que foi reduzido para o dízimo, a partir do Alvará, em 1803 (FEIGELSON, 2014).

Tanto o sistema Regaliano quanto a teoria do Metalismo, influenciaram a sociedade brasileira gerando consequências sociais e políticas na colônia; a exemplo, a Inconfidência Mineira, que consistiu num movimento separatista que ocorreu em 1789, tendo como principal motivo a incidência da derrama, que era uma cobrança instituída pela coroa portuguesa para a arrecadação, por parte da população, de valores, a fim de completar as cotas mínimas da exploração do ouro (FEIGELSON, 2014), já em decadência.

Após a Independência do Brasil, a lei de 1823 ratificou o sistema Regaliano, apenas o afinando à nova situação política. A Constituição de 1824 modificou esta configuração, pois entendia que os recursos minerais eram parte acessória do solo onde eles se encontravam; assim, quem fosse o detentor da propriedade seria detentor de todos os recursos minerais que pudesse extrair de seu subsolo. Tal sistema ficou conhecido como Acessão (BERCOVICl, 2011a). 
A garantia plena ao direito de propriedade manteve-se na Carta Magna de 1891, que inovou em definir, como competência da União, legislar sobre questões pertinentes ao Direito Minerário ${ }^{1}$. Sob este regime constitucional havia as minas de propriedade da União, as de propriedade dos Estados e as minas de propriedade particular.

Podemos visualizar, portanto, que primeiramente os bens minerais pertenciam à Coroa Portuguesa e, por um breve momento, passaram ao recente Estado Brasileiro independente, para que, por fim, com o reconhecimento da plenitude da propriedade, fosse para as mãos dos particulares, donos das propriedades, podendo, apenas, haver a limitação deste direito com o objetivo de trazer melhorias para a indústria da mineração, visando, desta forma, a um interesse maior, ou seja, a utilização dos recursos minerais como forma de obter desenvolvimento econômico.

\section{A NACIONALIZAÇÃO DOS RECURSOS MINERAIS E O INÍCIO DA ATUAÇÃO DE EMPRESAS ESTRANGEIRAS NO RAMO DA MINERAÇÃO NO BRASIL}

À partir de 1930 o Brasil verá uma enorme expansão de seu mercado interno, principalmente por força da industrialização. O nacionalismo econômico, promovido na época por Getúlio Vargas e seu Nacional Desenvolvimentismo, vai buscar maior independência econômica do país, quando se estabelecerá o controle do Estado sobre seus recursos minerais, pois se reconhecerá que tais recursos são estratégicos para o desenvolvimento nacional.

Segundo Caio Prado Júnior (1971, p. 269), em sua obra História Econômica do Brasil, em relação ao desenvolvimento da siderurgia no país,

Ainda ocorrerá outro obstáculo oposto a seu desenvolvimento: será o controle exercido sobre as principais jazidas brasileiras de ferro por grupos financeiros internacionais. Desde antes da guerra, vários desses grupos tinham adquirido a maior parte das vastas áreas do Estado de Minas Gerais onde se encontram as ocorrências do minério. Dentre elas se destaca a Itabira Iron Ore Co., ligada às casas Rothschild, Baring Bros. e E. Sassel, e que fêz suas aquisições em 1911. Mas o objetivo de tais grupos era apenas obter o controle das reservas brasileiras e impedir seu acesso a concorrentes; não se interessavam em explorá-las, e por isso permanecerão inativos, apesar dos contratos e obrigações em contrário existentes.

Assim sendo, é necessário fazer algumas ponderações acerca da participação de empresas estrangeiras em atividade no país. $O$ trecho retirado do livro de Caio Prado Júnior é o primeiro indício de que recursos estratégicos, como os recursos minerais e o petróleo, não devem ser explorados ou estar sob domínio externo. É por isso que será tão importante a nacionalização destes recursos feitos com a Revolução de 1930, que entrará em conflito tanto com a iniciativa privada nacional quanto com grandes grupos econômicos internacionais que sempre se fazem presentes, seja de forma direta ou indireta, no momento da definição sobre as políticas nacionais de aproveitamento dos recursos minerais.

A Constituição Federal de 1934, desta forma, modificou, de maneira brusca, os paradigmas do Direito Minerário (FEIGELSON, 2014), pois passou-se a aceitar o conceito dualista que separa as propriedades do solo com as do subsolo, ${ }^{2}$ além de condicionar a exploração dos recursos minerais a uma autorização ou concessão federal em seu artigo 119, porém dando preferência ao proprietário do solo na exploração das jazidas, em seu

\footnotetext{
BRASIL. Constituição da República dos Estados Unidos do Brasil de 1891. Diário Oficial da União. Rio de Janeiro, 1891. In verbis: “Art. 34 Compete privativamente ao Congresso Nacional:

[...]

29o) legislar sobre terras e minas de propriedade da União;" Disponível em: http://www.planalto.gov.br/ccivil_03/constituicao/ constituicao91.htm. Acesso em: 10 abr. 2019.

2 BRASIL. Constituição da República dos Estados Unidos do Brasil de 1934 (CF 34). Diário Oficial da União. Rio de Janeiro, 1934. In verbis: "Art. 118 - As minas e demais riquezas do subsolo, bem como as quedas d'água, constituem propriedade distinta da do solo para o efeito de exploração ou aproveitamento industrial." Disponível em: http://www.planalto.gov.br/ccivil_03/constituicao/constituicao34.htm. Acesso em: 1ํ abr. 2019.
} 
parágrafo 1‥ Ainda neste mesmo parágrafo percebe-se um viés nacionalista por parte da Carta Magna ao expressar que as autorizações ou concessões seriam oferecidas somente a brasileiros e a empresas organizadas no nosso país. ${ }^{3}$

Não foi sem resistência que tais mudanças foram recepcionadas. O Código de Minas de 1934 (Decreto no 24.642/34) recebeu uma enxurrada de críticas, e juristas defenderam sua inconstitucionalidade. O primeiro ponto levantado era a data de sua publicação, pois, apesar de ser datado no dia 10 de julho, só foi publicado no dia 20 de julho, ou seja, 4 dias depois da promulgação da CF de 1934, que se deu em 16 de julho de 1934. A questão é que o artigo 18 das Disposições Constitucionais Transitórias aprovou todos os atos do governo provisório somente até a data da promulgação da CF de 34. Como a publicação se deu depois da promulgação da Constituição, este motivo permitiria a alegação da inconstitucionalidade do Decreto. Além deste fator, outros, como a incorporação das jazidas desconhecidas ao patrimônio nacional, receberam alegações de inconstitucionalidade, pois feria o direito de propriedade e seu domínio ilimitado, que deveria também abranger a propriedade do subsolo (BERCOVICl, 2011a). Tais argumentações não encontraram respaldo na nova CF, que não somente consolidava o conceito dualista, mas também inseria a concepção de função social da propriedade, inspirada na Constituição de Weimar, e que limita o direito de propriedade em prol dos interesses sociais e coletivos.

A CF de 1937, promulgada no Estado Novo de Getúlio Vargas, manteve o viés nacionalista em relação ao subsolo e constitucionalizou o artigo 85 do Código de Minas de 1934, que previa a nacionalização progressiva de minas e jazidas que seriam consideradas essenciais econômica ou militarmente para o país. ${ }^{4}$

Em 1940 foi promulgado um novo Código de Minas (Decreto-Lei no 1985), que avançou mais um passo rumo à nacionalização dos recursos minerais e, em seu artigo 6ㅇ, determinou que as sociedades de mineração somente poderiam ter brasileiros como sócios. ${ }^{5}$ Houve também um aperfeiçoamento na distinção de mina e jazida, além de manter-se a concessão para a exploração da jazida, e enquanto esta não for concedida a mina não pode ser explorada de forma legítima (BERCOVICl, 2011a).

As Constituições de 1946 e de 1967 não apresentaram mudanças significativas em relação à exploração dos recursos minerais e à necessidade de concessão federal que será dada a brasileiros ou a sociedades organizadas no país (FEIGELSON, 2014). Nesta última, houve a inovação de garantir ao proprietário do solo a participação nos resultados da lavra, ${ }^{6}$ disposição que permanece até hoje.

A partir de 1964, entretanto, a política mineral no Brasil sofreu severas modificações visando a atender os interesses das empresas multinacionais, quando o artigo 60 do código de minas de 1940, mencionado anteriormente e que proibia empresas e sócios estrangeiros na mineração, foi considerada inconstitucional pelo Supremo Tribunal Federal. Como as Constituições de 1946 e de 1967 não possuíam restrições ao capital estrangeiro na mineração, e com a promulgação do código de mineração de 1967, que excluiu qualquer restrição à participação estrangeira na atividade minerária, observou-se um movimento muito forte de internacio-

\footnotetext{
CF 34. "Art. 119-O aproveitamento industrial das minas e das jazidas minerais, bem como das águas e da energia hidráulica, ainda que de propriedade privada, depende de autorização ou concessão federal, na forma da lei."

$\S 1$ - As autorizações ou concessões serão conferidas exclusivamente a brasileiros ou a empresas organizadas no Brasil, ressalvada ao proprietário preferência na exploração ou co-participação nos lucros." Disponível em: http://www.planalto.gov.br/ccivil_03/constituicao/ constituicao34.htm. Acesso em: 15 abr. 2019.

4 BRASIL. Constituição dos Estados Unidos do Brasil, de 10 de Novembro de 1937. Diário Oficial da União. Rio de Janeiro, 1937. In verbis:"Art. 144 - A lei regulará a nacionalização progressiva das minas, jazidas minerais e quedas d'água ou outras fontes de energia assim como das indústrias consideradas básicas ou essenciais à defesa econômica ou militar da Nação." Disponível em: http://www.planalto.gov. br/ccivil_03/Constituicao/Constituicao37.htm. Acesso em: 19 abr. 2019.

BRASIL. Decreto-Lei no 1985, de 29 de Janeiro de 1940. Código de Minas. Diário Oficial da União. Rio de Janeiro, 1940. In verbis: “Art. 60 0 direito de pesquisar ou lavrar só poderá ser outorgado a brasileiros, pessoas naturais ou jurídicas, constituídas estas de sócios ou acionistas brasileiros." Disponível em: https://www2.camara.leg.br/legin/fed/declei/1940-1949/decreto-lei-1985-29-janeiro-1940-412009-publicacaooriginal-1-pe.html. Acesso em: 20 maio 2019.

6 BRASIL. Constituição da República Federativa do Brasil de 1967. Diário Oficial da União. Brasília, 1967. In verbis: "Art. 161 - As jazidas, minas e demais recursos minerais e os potenciais de energia hidráulica constituem propriedade distinta da do solo para o efeito de exploração ou aproveitamento industrial.

$[\ldots]$

$\S 2$ ㅇ - É assegurada ao proprietário do solo a participação nos resultados, da lavra; quanto às jazidas e minas cuja exploração constituir monopólio da União, a lei regulará a forma da indenização." Disponível em http://www.planalto.gov.br/ccivil_03/constituicao/constituicao67.htm. Acesso em: 15 abr. 2019.
} 
nalização do aproveitamento dos recursos minerais brasileiros (BERCOVICl, 2011a). Tal ato se contradiz com o período histórico da Ditadura Militar, que, se por um lado era autoritário, em outras questões foi negligente, permitindo a ação incontrolada de empresas estrangeiras sobre recursos naturais estratégicos para o desenvolvimento econômico do Brasil.

\section{A ABORDAGEM NACIONALISTA DA CONSTITUIÇÃO FEDERAL DE 1988}

Os bens minerais constituem parte da riqueza de um determinado território, e tem o condão de revolucionar a economia de um país. Destarte, nossa Constituição de 1988 deu a esses bens um enfoque nacionalista, expressando em seu artigo 20, inciso IX, que os recursos minerais fazem parte dos bens da União.

Não se pode deixar bens tão importantes à mercê da decisão daqueles que são donos das propriedades onde estão localizadas reservas minerais, como minas de cobre, ouro, etc. A Carta Magna define como bem da União, para que esta decida a forma de exploração que se terá destes bens. Nas palavras de Nelson Ribeiro (1989, p. 70),

Reconheceu, assim, a Constituição, que os recursos minerais são bens econômicos que pertencem à sociedade como um todo. Por isso mesmo, não podem ser tratados como propriedade daquele que os descobrir, no seu exclusivo interesse particular, pois, seria uma violência contra o interesse social que é inerente à natureza desses bens.

O parâmetro nacionalista que a CF 88 impôs no parágrafo 10 do artigo $176,{ }^{7}$ foi alvo de polêmicas à época, pois o texto constitucional permitia apenas brasileiros ou empresas brasileiras de capital nacional (definido pelo artigo 171,11$)^{8}$ na pesquisa e lavra de recursos minerais, colocando o interesse nacional acima de qualquer outro, dando privilégios aos brasileiros e às empresas efetivamente brasileiras, ou seja, empresas onde quem detenha seu controle efetivo seja pessoa física residente e domiciliada no país, como definia o artigo 171, inciso II, revogado pela emenda de $n$ ㅇ 6 , que também modificou a redação do parágrafo 10 do artigo 176.

O capital estrangeiro não fica impedido de ser aplicado; contudo, como em uma empresa é o capital que define o poder decisório, a Carta Magna vem para garantir que este poder decisório esteja nas mãos de brasileiros em prol da nossa nação.

É importante frisar que as Disposições Transitórias trazem duas disposições que buscam realizar as mudanças de maneira não traumática. A primeira estabelece o prazo de 4 anos para que a iniciativa privada possa se nacionalizar, constante no artigo 44, caput, das Disposições Transitórias, e a segunda, presente no parágra-

\footnotetext{
7 BRASIL. Constituição da República Federativa do Brasil de 1988 (CF 88). Diário Oficial da União. Brasília, 1988. In verbis: "Art. 176. As jazidas, em lavra ou não, e demais recursos minerais e os potenciais de energia hidráulica constituem propriedade distinta da do solo, para efeito de exploração ou aproveitamento, e pertencem à União, garantida ao concessionário a propriedade do produto da lavra.

$\S 1$ ㅇ A pesquisa e a lavra de recursos minerais e o aproveitamento dos potenciais a que se refere o "caput" deste artigo somente poderão ser efetuados mediante autorização ou concessão da União, no interesse nacional, por brasileiros ou empresa brasileira de capital nacional, na forma da lei, que estabelecerá as condições específicas quando essas atividades se desenvolverem em faixa de fronteira ou terras indígenas - Revogado pela Emenda Constitucional no 6, de 15/08/95". Disponível em: http://www.planalto.gov.br/ccivil_03/constituicao/ constituicao.htm. Acesso em: 15 abr. 2019.

8 CF 88. In verbis:"Art. 171. São consideradas:

$[\ldots]$

II - empresa brasileira de capital nacional aquela cujo controle efetivo esteja em caráter permanente sob a titularidade direta ou indireta de pessoas físicas domiciliadas e residentes no País ou de entidades de direito público interno, entendendo-se por controle efetivo da empresa a titularidade da maioria de seu capital votante e o exercício, de fato e de direito, do poder decisório para gerir suas atividades. Revogado pela Emenda Constitucional no 6, de 15/08/95". Disponível em: http://www.planalto.gov.br/ccivil_03/constituicao/constituicao. htm. Acesso em: 15 abr. 2019.
} 
fo 1 10 deste mesmo artigo, dispõe uma exceção em relação às empresas brasileiras, ${ }^{9}$ que, mesmo não sendo de capital nacional, foram constituídas sob nossas leis, e, desta forma, poderão continuar com suas atividades, desde que industrializem o seu produto no país.

O produto mineral industrializado, segundo Nelson Ribeiro (1989), representa $25 \%$ do PIB, enquanto os minérios in natura não chegam nem aos $4 \%$, sendo de extrema importância para a política econômica do Brasil que estes produtos sejam manufaturados no país. Assim, o constituinte reconheceu que o maior significado econômico dos recursos minerais não está na sua simples extração e comercialização, mas, sim, no processo de industrialização que esses recursos poderiam ensejar.

\section{A EMENDA CONSTITUCIONAL № 6 DE 1995 E A PRIVATIZAÇÃO DA COMPANHIA VALE DO RIO DOCE}

O discurso populista de afastamento do Estado nas decisões e relações econômicas na década de 90 , fez que com diversas normas complementares à Constituição não fossem elaboradas, entre elas o novo Código de Mineração.

Uma reforma administrativa em 1990 extinguiu o Ministério de Minas e Energia, incorporando-o ao Ministério de Infraestrutura, desestabilizando a atuação de órgãos como o Departamento Nacional de Produção Mineral (DNPM), que, com a Lei no 8.876, de 2 de maio de 1994, a transformou em uma autarquia, mas sem lhe conceder todos os meios necessários para que o órgão pudesse fiscalizar o setor mineral e conceder licenças de forma adequada. A Companhia de Pesquisa de Recursos Minerais teve de licitar todas suas áreas pesquisadas e as repassar para a iniciativa privada (BERCOVICI, 2011a).

Rapidamente, a queda nos investimentos no setor de mineração foi atribuída às cláusulas nacionalistas e restritivas de capital contidas na CF de 1988, entrementes, em verdade, a realidade é que houve uma queda nos investimentos feitos pelo poder público (BERCOVICl, 2011a), mas o argumento prosperou e houve a aprovação da EC de no 6, de 15 de agosto de 1995, que modificou a orientação nacionalista no texto constitucional, firmada desde 1934.

A EC $n$ ㅇ 6 revogou o artigo 171, que diferenciava a empresa brasileira da empresa brasileira de capital nacional. Ou seja, a proteção a empresas autônomas, financeira e tecnologicamente, das multinacionais, foi retirada do texto constitucional, modificando a posição ideológica adotada pelo constituinte originário. $\mathrm{O}$ artigo 170, inciso IX, também foi modificado para garantir tratamento diferenciado às empresas brasileiras de pequeno porte, constituídas sob as leis brasileiras e com sede e administração no país, e não apenas às empresas brasileiras de capital nacional de pequeno porte.

O artigo 176, §1ํㅡ, também foi modificado, eliminando as restrições da exploração dos recursos minerais brasileiros para empresas multinacionais, bastando que constituam filial sob as leis brasileiras, com sede e administração no país. A lei de no 9.314 de 97 vem para regulamentar a participação do capital estrangeiro na mineração.

O Brasil, à época, tinha três empresas estatais responsáveis pela maior parte do desenvolvimento tecnológico do país e de sua infraestrutura. Tais empresas globais, pelo seu tamanho, capacidade técnica, financeira e organizacional para operar tanto no país como no exterior, eram a Companhia Vale do Rio Doce (CVRD), a Petrobrás e o Sistema Telebras. No Estado, contudo, ao invés de fortalecer estas empresas e dotá-las de maior capacidade operacional, reforçando o controle público e a transparência de seus recursos, o presidente Fernando Henrique Cardoso, em seu governo, optou por desmantelá-las, ao cortar investimentos e desestru-

\footnotetext{
BRASIL. Ato das Disposições Constitucionais Transitórias. In verbis: "Art. 44. As atuais empresas brasileiras titulares de autorização de pesquisa, concessão de lavra de recursos minerais e de aproveitamento dos potenciais de energia hidráulica em vigor terão quatro anos, a partir da promulgação da Constituição, para cumprir os requisitos do art. 176, § 1‥

$\S 1$ 1 Ressalvadas as disposições de interesse nacional previstas no texto constitucional, as empresas brasileiras ficarão dispensadas do cumprimento do disposto no art. 176, § 1ำ, desde que, no prazo de até quatro anos da data da promulgação da Constituição, tenham o produto de sua lavra e beneficiamento destinado à industrialização no território nacional, em seus próprios estabelecimentos ou em empresa industrial controladora ou controlada."

Disponível em: http://www.planalto.gov.br/ccivil_03/constituicao/constituicao.htm\#adct. Acesso em: 3 abr. 2019.
} 
turar suas finanças, com o objetivo de justificar a privatização da maior parte delas. Com a fragmentação das empresas estatais de infraestrutura, houve a substituição, na maioria dos casos, do monopólio estatal pelo monopólio ou oligopólio estrangeiro.

O governo Fernando Henrique Cardoso, ao privatizar a CVRD, ignorou o papel que esta empresa estatal tinha no desenvolvimento econômico regional do nosso país, e isso fez com que perdêssemos parte de nossa capacidade autônoma de decisão sobre a política econômica e uma empresa essencial para o planejamento do desenvolvimento nacional. A CVRD não era totalmente voltada para a mineração e exportação, mas possuía a capacidade autônoma de atrair investimentos e parcerias, considerada como um vetor de dinamização econômica e integração produtiva nacional (BERCOVICl, 2011a). Várias empresas, que se habilitaram para participar do leilão de privatização da Companhia Vale do Rio Doce, conseguiram informações estratégicas sobre os recursos minerais do nosso subsolo; empresas estas que eram competidoras da CVRD. Desta forma, as pesquisas e exploração mineral do nosso país ficaram nas mãos das empresas multinacionais.

\section{O CONTEXTO ATUAL DA EMENDA CONSTITUCIONAL № 6 DE 1995}

Sob um ponto de vista imperialista, a EC 6/95 explica-se, pois os Estados, em suas relações com os outros, atuam como se agentes privados fossem, em razão da estreita relação entre estes e o capital privado. 0 poder econômico, de fato, influencia o Estado a adotar normas legais de conteúdo econômico que sejam favoráveis a seus interesses, e tais medidas, que têm o condão de aumentar o crescimento econômico, acarretam uma maior arrecadação de tributos por parte do Estado. Tal fator, em uma economia capitalista como a nossa, é normal e, muitas vezes, favorável a ambas as partes. Segundo Vicente Bagnoli (2009, p. 68), entretanto,

Quando esses interesses privados decorrem de instituições cuja sede encontra-se no Império, os Estados podem acabar por sujeitarem-se aos mandos do Império, que atua em causa própria, ou seja, na própria defesa do interesse dos seus entes particulares que a eles estão associados, constituindo algo único.

Desta forma, em consonância com esse pensamento, Washington Peluso Albino de Souza (2002, p. 545) afirma acerca da aprovação da Emenda Constitucional no 6/95:

Podemos considerar esta modificação como modalidade de "abertura" da economia brasileira pela "inclusão" dos capitais estrangeiros, mas havemos de aquilatar também os consequentes efeitos de "exclusão" dos nacionais ante à nossa reconhecida condição de economia periférica, em inferioridade de recursos competitivos.

Assim, é válido afirmar que a emenda possibilitou a "inclusão" do capital estrangeiro no setor da mineração ao preço da efetiva "exclusão" do capital nacional, pois, ao retirar da Constituição Federal a distinção entre empresa de capital nacional e empresa de capital estrangeiro, permitiu que este pudesse ser investido no setor de mineração brasileiro massivamente. Segundo dados do Instituto Brasileiro de Mineração (Ibram), no período de 2012-2016 foi registrado pelo Instituto a aplicação de US\$ 75 bilhões, representando um novo recorde para o setor no Brasil (IBRAM, 2015).

O que se observa é que atualmente a mineração brasileira exporta apenas commodities, ou seja, produtos que passaram por quase nenhum tipo de processo que lhes agregue valor. Conforme dados do Ibram (2019), em seu relatório anual de 2018-2019,68\% das exportações minerais do Brasil são de minério de ferro, que, de acordo com o site da Vale (2019), ${ }^{10}$ maior produtora deste minério no Brasil, consiste na forma mais rudimentar do ferro. Este sim é utilizado grandemente na indústria e pode ser obtido por meio de um longo processo de transformação fabril do minério de ferro, mas tal processo não se dá em nosso país, apenas a extração. Outro minério no qual o Brasil é um dos maiores exportadores do mundo é a bauxita, que é a forma primária do alumínio (BAUXITA, 2019), material de extrema importância para a indústria mundial. Assim sendo, podemos perceber que esse aporte de investimentos estrangeiros não vem para o país de forma a gerar inovação e desenvolvimento da indústria local; o que se busca são recursos minerais de baixo valor agregado para serem utilizados na indústria destes mesmos países como matéria-prima.

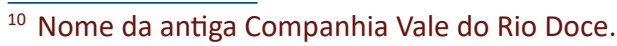


Outra consequência da EC 6/95 é que a tecnologia necessária para realizar a atividade minerária não é produzida no país, ou seja, não se introduziu uma estrutura de desenvolvimento tecnológico e inovação voltada a criar novas máquinas e/ou melhorar os processos de extração mineral no país, exatamente porque objetiva-se suprir uma demanda externa. $\mathrm{O}$ aparelhamento utilizado não é produzido nacionalmente, e, portanto, não há difusão tecnológica, pois a tecnologia necessária vem de fora para ser aplicada aqui (MONTEIRO, 2005).

Com relação à soberania econômica, que está prevista no artigo $170,1,{ }^{11}$ da Constituição Federal, precisamos nos atentar que tal disposição objetiva tornar possível a participação da sociedade brasileira, em condições de igualdade, no mercado internacional, com o objetivo maior de garantir o desenvolvimento nacional presente no artigo 3으. II, da CF. ${ }^{12}$ Destarte, diversos dispositivos na Constituição vigente têm como objetivo a redução das vulnerabilidades externas do país, para que possamos resistir a desestabilizações e choques econômicos alheios ao nosso controle. Entende-se por soberania econômica a capacidade de decidir acerca das políticas econômicas de forma autônoma (BERCOVICI, 2011b).

Quando a Constituição trouxe a distinção entre empresa brasileira e empresa brasileira de capital nacional, diferenciando, assim, o capital estrangeiro do nacional, buscava-se privilegiar as empresas nas quais seu controle estava, efetivamente, no poder de agentes econômicos nacionais com o escopo de fomentar o desenvolvimento econômico e tecnológico do país. A questão do capital estrangeiro e sua distinção com o nacional sempre esteve atrelada às decisões de impacto político e econômico, que, em alguns casos, como o da mineração, foi transferida para o exterior.

A exclusão da verdadeira empresa brasileira e a anulação de suas defesas, antes garantidas pelo texto constitucional, fez com que esta sofresse perdas em relação a sua capacidade de produção e comercialização, ficando dependente da tecnologia estrangeira e padecendo da falta de recursos em razão da própria descapitalização da economia nacional, que coloca estas empresas em inferioridade na concorrência dos mercados, tanto nacional quanto internacional (SOUZA, 2002).

A política mineral brasileira encontra-se num momento em que há um número imenso de exportação de produtos que não sofreu quase nenhuma transformação industrial. A década de 90 foi marcada como um período de forte desindustrialização, que se diferencia de outros países mais desenvolvidos, quando houve a transferência da indústria pesada para outros setores mais tecnologicamente avançados, ou para o setor de serviços, tendo ocorrido no Brasil, em sentido contrário, uma regressão, e a mão de obra foi transferida para o setor agrário ou para o setor minerador extrativo, a exemplo, havendo um aumento na exportação de produtos primários de baixo valor agregado, ocorrendo uma baixa no dinamismo econômico e o desemprego (BERCOVICl, 2011a).

Como ressalta Bercovici (2011b), no entanto, nada impede que a legislação ordinária estabeleça certas distinções favorecendo o empreendimento de capital nacional em detrimento daquele de capital estrangeiro, pois a revogação do artigo 171 da CF/88 apenas estabelece uma situação em que não há mais o imperativo constitucional em realizar esta distinção, pois a preferência antes era obrigatória.

Tais distinções em benefício da empresa de capital nacional encontram respaldo em diversos dispositivos da Constituição Federal de 1988. Além do já citado artigo 3, inciso II, que trata da garantia do desenvolvimento nacional como um dos objetivos fundamentais da República, e o artigo 170, que, em seu inciso I coloca

\footnotetext{
${ }^{11}$ CF 88: "Art. 170. A ordem econômica, fundada na valorização do trabalho humano e na livre-iniciativa, tem por fim assegurar a todos existência digna, conforme os ditames da justiça social, observados os seguintes princípios:

I - soberania nacional; [...]". Disponível em: http://www.planalto.gov.br/ccivil_03/constituicao/constituicao.htm. Acesso em: 29 out. 2019.

${ }^{12}$ CF 88: "Art. 3ํㅡㄴ Constituem objetivos fundamentais da República Federativa do Brasil:

$[\ldots]$

II - garantir o desenvolvimento nacional; [...]". Disponível em: http://www.planalto.gov.br/ccivil_03/constituicao/constituicao.htm. Acesso em: 29 out. 2019.
} 


\section{Direitol Debate}

como princípio da ordem econômica a soberania nacional, temos os artigos 218 caput e $\S 1$ e e 219 caput, ${ }^{13}$ que tratam sobre o incentivo que deve ser provido pelo Estado ao desenvolvimento científico, à inovação e à autonomia tecnológica. Assim sendo, o Estado pode adotar uma postura mais protetiva, contornando os efeitos da $\mathrm{EC}$ no 6/95, principalmente em relação à gestão dos recursos minerais.

\section{CONCLUSÃO}

Observamos que, ante o passado extrativista dos recursos minerais e os seus primeiros impulsos regulatórios no período pós-independência, quando se reconheceu a plena propriedade privada, não havendo separação dos bens do solo e do subsolo, sua exploração nunca foi, de fato, totalmente separada do interesse nacional, pois poderia ser limitada, visando o desenvolvimento econômico. A revolução de 1930 e o Nacional Desenvolvimentismo de Getúlio Vargas buscou centralizar, de maneira mais intensa, a exploração destes recursos, promovendo sua ampla nacionalização, de forma a desenvolver a indústria nacional. Esta perspectiva nacionalista, mesmo tendo sido flexibilizada no período do regime militar, foi reforçada pela Constituição Federal de 1988. Como restou demonstrado neste trabalho, no entanto, a aprovação da EC no 6 de 1995 e a modificação que esta provocou na posição ideológica adotada originariamente pela CF de 1988 em relação à exploração dos bens minerais, representou um retrocesso para o desenvolvimento industrial do nosso país.

Os recursos minerais fazem parte de nossa riqueza, mas a aprovação da emenda fez com que diversas empresas estrangeiras adquirissem empresas brasileiras (MONTEIRO, 2005), resultando num processo de grande concentração de capitais e pouquíssima difusão de tecnologia de mineração. O controle do capital não é feito em âmbito nacional, e o que se percebe é que não se consegue enraizar um processo de desenvolvimento econômico regional. O país perdeu grande parte do controle dos recursos minerais e parte do potencial em desenvolver suas indústrias e tecnologias, dando espaço à ampla exportação dos commodities e se desindustrializando.

Para a superação desta problemática, o país necessita de uma reestruturação produtiva e tecnológica, adotando uma política mineral que busque favorecer a empresa de capital nacional em detrimento da empresa de capital estrangeiro (estando esta ação respaldada pela Constituição e podendo ser feita por meio de lei ordinária), além de um Estado forte e empreendedor que seja capaz de retomar o processo de desenvolvimento encarando os recursos minerais como recursos estratégicos, capazes de dinamizar e fortalecer a indústria nacional, abandonando as políticas privatizantes e promovendo uma integração social e política de toda a população, em vistas de construir um Estado verdadeiramente autônomo.

Por fim, retornamos aos ensinamentos de Celso Furtado, de que, para nós, países de periferia, o desenvolvimento é um mito. Acreditamos que podemos ter os mesmos padrões de consumo que um país considerado de centro, mas, enquanto formos meros exportadores de seus itens de necessidade, e não produtores de novas tecnologias e pesquisas sustentáveis (CAVALCANTI, 2003), ainda estaremos correndo atrás deste mito.

\section{REFERÊNCIAS}

BAGNOLI, Vicente. Direito e poder econômico: os limites jurídicos do imperialismo frente aos limites econômicos da soberania. Rio de Janeiro: Elsevier; Campus Jurídico, 2009.

BAUXITA. Mineração Rio do Norte. Disponível em: http://www.mrn.com.br/paginas/pt/sobre-a-mrn/perfil/bauxita.html. Acesso em: 27 ago. 2019.

BERCOVICI, Gilberto. Direito econômico do petróleo e dos recursos minerais. São Paulo: Ed. Quartier Latin, $2011 \mathrm{a}$.

\footnotetext{
${ }^{13}$ CF 88:

“Art. 218. O Estado promoverá e incentivará o desenvolvimento científico, a pesquisa, a capacitação científica e tecnológica e a inovação (Redação dada pela Emenda Constitucional no 85, de 2015).

$\S 1$ 을 A pesquisa científica básica e tecnológica receberá tratamento prioritário do Estado, tendo em vista o bem público e o progresso da ciência, tecnologia e inovação. (Redação dada pela Emenda Constitucional no 85, de 2015).

[...]

Art. 219. O mercado interno integra o patrimônio nacional e será incentivado de modo a viabilizar o desenvolvimento cultural e sócio-econômico, o bem-estar da população e a autonomia tecnológica do País, nos termos de lei federal. [...]". Disponível em: http://www.planalto. gov.br/ccivil_03/constituicao/constituicao.htm. Acesso em: 24 out. 2019.
} 
BERCOVICl, Gilberto. Soberania econômica e regime jurídico do capital estrangeiro no Brasil. Revista Brasileira de Estudos Constitucionais - RBEC, Belo Horizonte, ano 5, n. 17, p. 95-110, jan./mar. 2011b.

BRASIL. Ato das Disposições Constitucionais Transitórias. Diário Oficial da União. Brasília, 1988a. Disponível em: http://www. planalto.gov.br/ccivil_03/constituicao/constituicao.htm\#adct. Acesso em: 3 out. 2019.

BRASIL. Constituição da República Federativa do Brasil de 1988 (CF 88). Diário Oficial da União. Brasília, 1988b. Disponível em: http://www.planalto.gov.br/ccivil_03/constituicao/constituicao.htm. Acesso em: 2 out. 2019.

BRASIL. Constituição da República Federativa do Brasil de 1967. Diário Oficial da União. Brasília, 1967. Disponível em: http:// www.planalto.gov.br/ccivil_03/constituicao/constituicao67.htm. Acesso em: 1o out. 2019.

BRASIL. Constituição da República dos Estados Unidos do Brasil de 1934 (CF 34). Diário Oficial da União. Rio de Janeiro, 1934. Disponível em: http://www.planalto.gov.br/ccivil_03/constituicao/constituicao34.htm. Acesso em: 10 out. 2019.

BRASIL. Constituição da República dos Estados Unidos do Brasil de 1891. Diário Oficial da União. Rio de Janeiro, 1891. Disponível em: http://www.planalto.gov.br/ccivil_03/constituicao/constituicao91.htm. Acesso em: 10 out. 2019.

BRASIL. Decreto-Lei no 1.985, de 29 de Março de 1940. Código de Mina. Diário Oficial da União. Rio de Janeiro, 1940. Disponível em: http://www.planalto.gov.br/ccivil_03/Decreto-Lei/1937-1946/Del1985.htm. Acesso em: 15 out. 2019.

BRASIL. Constituição dos Estados Unidos do Brasil, de 10 de Novembro de 1937. Diário Oficial da União. Rio de Janeiro, 1937. Disponível em: http://www.planalto.gov.br/ccivil_03/Constituicao/Constituicao37.htm. Acesso em: 15 out. 2019.

CAVALCANTI, Clóvis. Meio Ambiente, Celso Furtado e o Desenvolvimento como Falácia. Ambiente \& Sociedade, vol. V, n. 2, ago./dez. 2002; vol. VI, n. 1, jan./jul. 2003. Disponível em: http://www.scielo.br/pdf/asoc/v5n2/a05v5n2.pdf. Acesso em: 3 out. 2018.

FEIGELSON, Bruno. Curso de Direito Minerário. São Paulo: Ed. Saraiva, 2014.

IBRAM. Instituto Brasileiro de Mineração. Informações sobre a Economia Mineral Brasileira 2015. Brasília, 2015. Disponível em: http://www.ibram.org.br/sites/1300/1382/00005836.pdf. Acesso em: 25 ago. 2019. p. 18.

IBRAM. Instituto Brasileiro de Mineração. Relatório Anual de Atividades: julho de 2018-junho de 2019. Disponível em: http:// portaldamineracao.com.br/ibram/wp-content/uploads/2019/07/relatorio-anaul-2018-2019.pdf. Acesso em: 25 ago. 2019. p. 43.

MINÉRIO DE FERRO E PELOTAS. Vale. Disponível em: http://www.vale.com/brasil/PT/business/mining/iron-ore-pellets/Paginas/default.aspx. Acesso em: 27 ago. 2019.

MONTEIRO, Maurílio de Abreu. Meio século de mineração industrial na Amazônia e suas implicações para o desenvolvimento regional. Estudos Avançados, São Paulo, v. 19, n. 53, jan./abr. 2005. Disponível em: http://www.scielo.br/scielo.php?script=sci_arttext\&pid=S0103-40142005000100012. Acesso em: 29 set. 2019.

PRADO JÚNIOR, Caio. História econômica do Brasil. 14. ed. São Paulo: Brasiliense, 1971.

RIBEIRO, Nelson. As macroperspectivas do Direito minerário a partir da nova Constituição. Revista de Informação Legislativa, a. 26, n. 102, abr./jun. 1989.

SOUZA, Washington Peluso Albino de. Teoria da Constituição Econômica. Belo Horizonte: Del Rey, 2002. 